brazilianpoliticalsciencereview

ART I CLE

\title{
Biopiracy after the Nagoya Protocol: Problem Structure, Regime Design and Implementation Challenges*
}

\section{Florian Rabitz}

Vrije Universiteit Brussels, Belgium

\begin{abstract}
This article assesses the effectiveness of the 2010 Nagoya Protocol to the Convention on Biological Diversity (CBD) for addressing "biopiracy" of genetic resources; that is, their biotechnological utilization in violation of either the provider country legislation or mutually agreed contractual obligations. Biopiracy is defined as a problem resulting from a distributive conflict between provider and user countries, the practical difficulties of monitoring the utilization of genetic resources in a transnational context, and the pervasive scientific uncertainty about the nature and extent of the problem. The Nagoya Protocol predominantly focuses on compliance management while lacking the necessary enforcement provisions for deterring noncompliance through effective monitoring and sanctions. Using the example of recent European Union implementing legislation, this article underscores how parties may use the Protocol's legal ambiguities to soften its regulatory impact on domestic industry. As a result, in light of both problem structure and regime design, the Protocol only offers modest improvements over the status quo ante.
\end{abstract}

Keywords: Biodiversity; biotechnology; compliance; regime effectiveness; North-South relations. 
ince the 1980s, plant genetic resources (GR) are increasingly being

used for biotechnological research and development. While the largest share of global plant biodiversity is concentrated in several countries of the Global South, the technological capacities for transforming genetic raw materials into commercially viable products, from pharmaceuticals to cosmetics up to improved varieties of crops, are predominantly found in industrialized countries. GR had been available to commercial and non-commercial users without restrictions under the 1983 International Undertaking on Plant Genetic Resources, being considered part of the "common heritage of mankind" (International Undertaking, Article 01). Developing countries with large amounts of domestic plant biodiversity began challenging this open access regime when unrestricted SouthNorth germplasm flows translated increasingly into Intellectual Propertyprotected inventions, with the resulting economic benefits being appropriated by private entities originating from the Global North (BRAND et al., 2008; ROSENDAL, 2000).

The term "biopiracy" loosely refers to "the use of intellectual property systems to legitimize the exclusive ownership and control over biological resources and biological products that have been used over centuries in nonindustrialized cultures" (SHIVA, 2001. p. 49). Since the 1990s, a number of high profile cases of biopiracy have been the subject of intense controversies (BARDI et al., 2011; HAMILTON, 2006; LIANG, 2011; MGBEOJI, 2006; ROBINSON, 2010). In parallel, conflicts regarding the role of the World Trade Organization (WTO) in global governance quickly extended to the linkage between biopiracy and international patent law. Since the late 1990s, biopiracy has been under discussion in various international settings, from the WTO and its Agreement on TradeRelated Aspects of Intellectual Property Rights (TRIPS), the World Intellectual Property Organization (WIPO), the Food and Agriculture Organization (FAO), the Convention on Biological Diversity (CBD) and the World Health Organization (WHO) (ANDERSEN, 2008; VIVAS-EUGUI, 2012; WILKE, 2013). In 2004, the CBD's Conference of the Parties (COP) mandated negotiations on an international regime for implementing the Convention's objective of the "fair and equitable sharing of the benefits arising out of the utilization of genetic resources" (CBD Article 01). This led to the conclusion, in October 2010, of the Nagoya Protocol on Access to 
Genetic Resources and the Fair and Equitable Sharing of Benefits Arising from their Utilization (Nagoya Protocol). The Protocol has been signed by 91 states and the European Union (EU), and entered into force on 12 th October 2014.

The Protocol is presently the only international agreement providing a comprehensive legal framework for addressing biopiracy, here understood as the utilization of GR without the provider country's consent or in violation of mutually agreed contractual terms. Drawing on the literature on regime effectiveness (HOVI et al., 2003; MITCHELL, 2006; UNDERDAL, 2002), I assess the degree to which Protocol will contribute to fair and equitable benefit-sharing. First, focusing on problem structure and regime design, I argue that biopiracy is a particularly malignant problem resulting from distributional conflicts between (private) users and provider countries ${ }^{1}$, the technical difficulty of monitoring utilization of GR in a transnational context, and the international constellation of interests. Second, I make the case that the Protocol emphasizes compliance management over enforcement, which will likely be insufficient to ensure fair and equitable benefitsharing in those cases where commercial stakes are involved. Third, I show that its legal ambiguities allow for the implementation of legislation to minimize the regulatory impact on domestic users. In sum, the Protocol is a weak response to a difficult problem.

The rest of this text is organized as follows. Section 02 addresses biopiracy in the context of biotechnology and intellectual property rights. I highlight the North-South dimension of biopiracy while showing that the problem is characterized by significant conceptual ambiguity as well as uncertainty regarding its extent and economic costs. Section 03 introduces the theoretical framework, drawing on the literature on regime effectiveness and compliance. Section 04 assesses the problem structure of biopiracy, arguing that both the international constellation of interests and the difficulties related to transnational monitoring and enforcement significantly complicate effective international action. Section 05

\footnotetext{
${ }^{1}$ The term "user" here refers to commercial (i.e., multinational companies in sectors such as pharmaceuticals, agriculture or cosmetics) and non-commercial actors (i.e., public research institutions or botanical gardens) that use GR in a broad range of biotechnological innovation processes. The term "user country" broadly refers to countries with relatively large amounts of users under their jurisdiction, being frequently identical with "industrialized country". Where necessary, I use the term "private users" in order to avoid terminological confusion.
} 
turns to the relevant provisions under the CBD. While "biopiracy" is not defined under international law, the CBD's provisions distinguish between two types: the acquisition of GR in violation of a provider country's domestic laws and regulations on the one hand, and their utilization in breach of contractual agreements between the user and provider countries on the other hand. Section 06 analyzes the relevant provisions of the Nagoya Protocol, arguing both that its enforcement components are insufficient for deterring intentional non-compliance based on cost-benefit analysis and that the ambiguity of the legal text allows for flexible implementation in user countries wishing to cushion its domestic impact. However, the provisions on international access standards will facilitate compliance with provider country legislation by reducing legal uncertainty, transaction costs and cumbersome bureaucratic procedures. Section 07 analyzes the Protocol's implementation in the EU which, of all parties, possesses the largest market for biotechnology. I show that the implementing regulation emphasizes management over enforcement and exploits a critical loophole regarding the Protocol's temporal scope. Section 08 concludes this article.

\section{The political and economic context}

The expression "genetic resources" broadly encompasses the microphysical properties of biological materials from plant, microbial, animal and other sources as well as the genetic information which those materials contain (TVEDT and SCHEI, 2014). GR find application in a broad number of industrial processes, ranging from pharmaceuticals to cosmetics up to agricultural and industrial applications. While the technological capacities for the utilization of GR are concentrated in industrialized countries, the highest levels of biodiversity, and thus of potentially valuable materials, are found in developing countries. In 2006, $41.5 \%$ of international applications for biotechnology patents under the Patent Cooperation Treaty originated in the US, $27.4 \%$ in the EU, $11.9 \%$ in Japan and 4\% in the BRIICS countries (Brazil, Russian Federation, India, Indonesia, China and South Africa) (VAN BEUZEKOM and ARUNDEL, 2009, p. 71). At the same time, 44\% of all vascular plants worldwide are concentrated in 25 biodiversity hotspots, most of them located in the Global South, such as South-East Asia, Brazil, Chile, Ecuador and Madagascar (MYERS et al., 2000). 
The term "biopiracy" came to prominence in the late 1990s. On a general level, it refers to the commercial utilization of GR (frequently originating in developing countries) for the development of inventions protected by patents or plant variety rights (SHIVA, 2001). This poses two distinct problems. First, market access for protected goods containing GR may become subject to restrictions, as authorization by the rights holder is required for, inter alia, import and export (TRIPS Article 28.1.a; UPOV Convention Article 1.a.v-vi). Second, most states, with the notable exception of the US, have committed themselves to ensuring that any benefits arising from the utilization of GR are shared fairly and equitably with the provider country (CBD Article 01; see Section 05 below). In practice, this objective is relatively easy to circumvent by commercial actors eager to avoid potentially costly compensation schemes.

Evidence of biopiracy is mainly anecdotal, and comprehensive assessments of its global costs do not exist. As it is considered an illegal activity under the domestic laws of many provider countries (RENNER et al., 2012), it is relatively easy to avoid detection when illegally accessing GR (see Section 04 below). Without a global tracking mechanism for the use of GR in patent applications, calculating the frequency with which biopirated materials are utilized in various innovation processes is next to impossible. More fundamentally, any cost assessment needs a counterfactual baseline of the benefits that would be received by a provider country, if biopiracy were absent and bilateral benefitsharing arrangements had been negotiated between the user and the provider country. However, calculating the opportunity costs of biopiracy based on the outcomes of hypothetical negotiation, involving significant uncertainty about the future commercial value of inventions developed through the utilization of GR, is not feasible.

While biopiracy is not a defined term under international law and is insufficiently understood in its economic dimensions, a range of anecdotal episodes exist which are widely recognized as instances of biopiracy (see ROBINSON, 2010 for a comprehensive overview):

- In 1995, a patent for an antifungal product was granted by the European Patent Office (EPO) to the US Department of Agriculture and the US-American firm W.R. 
Grace and Company, incorporating genetic materials from the Neem tree found in India and Nepal. Components of the Neem tree have been used for traditional medicine and cooking for about 2000 years. However, no benefit-sharing arrangements were agreed between the users and the Indian authorities. The EPO patent was successfully challenged by India on the basis of a prior art claim, leading to its revocation in 2005 (SHERIDAN, 2005).

- In 1999, the US Patent and Trademark Office (USPTO) granted a patent on the socalled "Enola Bean", primarily produced in Mexico for export to the US market. The patent grant was based on the "distinctness" of the bean's yellow color under the 1930 Plant Patent Act. The rights holder initiated patent litigation against importers that refused to pay royalties (RATTRAY, 2002). In 2008, a US federal court revoked the patent due to a lack of novelty and non-obviousness.

- The Hoodia plant has been traditionally used by the native San people in the Kalahari Desert. Being a natural appetite suppressant, it allows the San to hunt for prolonged periods of time. A patent for a dietary product based on Hoodia was granted to the South African Council for Scientific and Industrial Research (CSIR) in 1997, subsequently licensed first to the UK-based company Phytopharm and afterwards to the Anglo-Dutch company Unilever. Due to political and public pressure, CSIR agreed to enter into a benefit-sharing agreement with the San people, whereby they would receive royalties of between $06-08 \%$ of commercial profits (WYNBERG and CHENNELLS, 2009).

What these examples have in common are conflicts arising from the intersection between sovereignty claims over GR and intellectual property claims based either on their immediate parts or on inventions resulting from their biotechnological utilization. The differing interests of provider and user countries complicate an effective international response to biopiracy, in addition to aggravating various problems involving the transnational regulation of private agents (see Section 04). As I show in the remainder of this text, both the problem structure of biopiracy and the rule design of the Nagoya Protocol lead to low regime effectiveness in terms of ensuring that users comply with their benefitsharing obligations in a transnational context. 


\section{lopsr - Biopiracy after the Nagoya Protocol: Problem Structure, Regime Design and Implementation Challenges}

Theoretical framework: regime effectiveness and compliance

Environmental regimes differ in the degree to which they achieve their respective objectives (BREITMEIER et al., 2011). Research on the determinants of regime effectiveness broadly distinguishes between institutional influence and problem structure (MITCHELL, 2006; UNDERDAL, 2002): while the particular design of an international regime may be more or less conducive to the achievement of a given objective, some problems are intrinsically more difficult to solve than others, independent of any rules that states agree on. All assessments of regime effectiveness thus need to take into account the particular problem which the regime is supposed to address. I follow the general proposition that the political malignancy of a problem depends on the international constellation of interests (UNDERDAL, 2002). "Easy" problems are those where interests significantly overlap. Where interests diverge due to a regime's potential to produce highly asymmetrical effects, in terms of costs and benefits, regime formation becomes politically difficult and there will be incentives to defect during the implementation phase. This issue is exacerbated by the difficulty of monitoring the utilization of GR in a transboundary context. As Section 04 shows, biopiracy is characterized by a high degree of problem malignancy, decreasing the extent to which internationally agreed rules can contribute to fair and equitable benefitsharing while creating incentives for implementing those rules in a manner that decreases their regulatory scope and depth.

In this text, I assess effectiveness at the level of outputs; that is, the extent to which a regime's rules restructure (private) actors' incentives in order to bring their behavior in line with a specific policy objective. While effectiveness may also be evaluated by directly observing behavioral changes in those agents subject to a regime's rules (YOUNG, 2001), any direct observation of biopiracy faces formidable methodological challenges. In addition, with the Nagoya Protocol having been entered into force only on $12^{\text {th }}$ October 2014, any resultant behavioral changes at the unit level would not have the extended period of time required for observation. In the present text, I accordingly understand "effectiveness" as the degree to which the Protocol and the parties implementing legislation shape incentive structures, with the ultimate goal of having users fairly and equitably share the benefits arising from the utilization of GR with provider countries and 
without, however, attempting to directly observe eventual behavioral changes by private users. As Sections 05 and 06 spell out in more detail, the Convention and the Protocol establish a procedural standard whereby benefit-sharing is "fair and equitable" if users abide by the contractual obligations that have been mutually agreed between them and the provider country, or if the provider country waives its right to require benefit-sharing in the first place.

"Effectiveness" is a relational term. In order to assess regime effectiveness, we require a baseline against which to compare a regime's actual performance. The "Oslo-Potsdam solution" proposes two different standards of evaluation based on counterfactual analysis: comparing regime performance to a no-regime scenario; and comparing performance to a hypothetical collective optimum (HELM and SPRINZ, 2000; HOVI et al., 2003; YOUNG, 2003). The no-regime counterfactual allows determination of the degree to which a regime "matters": that is, how far it induces behavioral changes relative to business-as-usual. The use of a collective optimum as a baseline focuses on the degree to which a regime contributes to problem-solving. Both metrics will be used in this paper, and I show that the Nagoya Protocol improves the status quo ante by facilitating user compliance with the domestic laws and regulations of provider countries. However, it fails to raise the costs of non-compliance within those jurisdictions in which utilization takes place, thus insufficiently restructuring the incentives of users to ground their decision, of whether or not to comply, on cost-benefit analysis.

Accordingly, as user compliance is critical for the Protocol's effectiveness, I draw on the well-established distinction between enforcement- and managementbased approaches to compliance. The former assumes rational actors which weigh the cost of compliance against the risk of non-compliance, the latter being a function of the expected sanctions and the likelihood of being detected as noncompliant (DOWNS et al., 1996; GUNNINGHAM and KAGAN, 2005). Conversely, the management approach understands rules not as deterring and constraining, but as enabling and facilitating (CHAYES and CHAYES, 1993; KRATOCHWIL, 2011; MAY, 2005). Here, actors are biased towards complying with their obligations due to the internalization of social norms, with non-compliance resulting from incapacity or rule ambiguity. The management- and enforcement-based approaches thus propose different ways to ensure that rules are being followed: facilitating 
compliance through capacity building and the creation of rules that are easy to follow on the one hand, increasing monitoring capacities and sanctions on the other. My argument does not commit to whether one or the other approach is superior. As Section 06 shows, the Nagoya Protocol emphasizes management over enforcement. While this may ameliorate problems of involuntary non-compliance, it is insufficient to deter users that weigh the costs of benefit-sharing, and of transactions associated with the negotiation of benefit-sharing arrangements, against the expected sanctions resulting from being found in non-compliance. Theory suggests that, where actors have well-established preferences as well as knowledge of the likely consequences of pursuing those preferences, their behavior tends towards rational cost-benefit calculation (MARCH and OLSEN, 1998, pp. 952-953). Thus, where commercial stakes are involved, the relative lack of enforcement provisions in the Protocol will matter more than in cases where GR are being utilized for non-commercial purposes, such as basic research.

\section{The problem structure of biopiracy}

Biopiracy is characterized by high problem malignancy. User countries (primarily industrialized ones) are biased towards the benefits of biopiracy, that is, the appropriation of GR by domestic users without entering into negotiated payment schemes. For provider countries (primarily developing ones), the costs of biopiracy entail both opportunity costs (through lost benefit-sharing arrangements) and potential difficulties with market access in the case of goods containing GR being patent-protected in export markets (ROBINSON, 2010). This bias towards the benefits and costs of biopiracy, respectively, is compounded by difficulties related to monitoring and enforcement.

First, access to GR in violation of a provider country's domestic laws and regulations cannot effectively be prevented. While a number of provider countries have legislation in place which criminalizes the unauthorized export of domestic plant and animal species (RENNER et al., 2012), many biotechnological applications do not require bulk commodities of a particular GR but merely its genetic code. While customs authorities are, at least in principle, able to detect the illegal export of singular plant samples, modern information technology allows for 
DNA to be sequenced within a provider country and resulting sequence data to be digitally transmitted to third countries with minimal risk of detection.

Secondly, once GR have been illegally acquired, fulfillment of the benefitsharing objective hinges on monitoring and enforcement in user jurisdictions. Here, the incorporation of GR in patent applications requires a system by which legally-accessed resources may be distinguished from illegally-accessed ones, with appropriate legal remedies for the latter case. For instance, a number of proposals have been made for a disclosure of origin requirement, which would require patent applicants to provide evidence that any GR utilized within their inventions have been accessed legally and in line with the benefit-sharing objective (CORREA, 2005; HOARE and TARASOFSKY, 2007). Nevertheless, there are legal concerns that a disclosure requirement in patent law would go beyond the substantial and formal patentability criteria contained in TRIPS Articles 27.1 and 29, and would be incompatible with the Article 27.1 prohibition of discriminatory treatment for specific fields of technology.

An additional challenge arises from the necessity of implementing compliance measures in user countries. States with large domestic biotech sectors lack economic incentives for enforcing the benefit-sharing objective under their domestic patent laws. Such "strong" enforcement could range from patent applications not being processed, in the case of non-disclosure of the origin of GR used in the respective inventions, up to the revocation of patents already granted. Here, the position of major user countries, such as the US, is that acts of biopiracy can be dealt with effectively under existing, domestic patent law (UNITED STATES, 2005). For instance, a patent granted for an invention incorporating misappropriated GR could be successfully challenged on the basis of a prior art claim, invalidating the patent due to a lack of novelty.

Biopiracy is thus characterized by diverging interests between provider and user countries of GR. Moreover, the possibilities for realizing joint gains are limited, as benefit-sharing arrangements are frequently zero-sum games between user and provider countries. While user countries have an interest in international cooperation in order to facilitate access to GR by users within their jurisdictions (WALLBOTT et al., 2014, pp. 38-39), they are in a relationship of asymmetrical interdependence with provider countries: access to GR depends less on 
international cooperation than does benefit-sharing, the latter requiring extensive regulatory and legislative adjustments in user countries. Thus, based on the international constellation of interests, the lack of economic incentives for the voluntary sharing of benefits and the significant technical and legal impediments to the effective implementation of the benefit-sharing objective in a transnational context, not only does biopiracy constitute a "hard" problem for international cooperation, but the regime design itself, both of the CBD and the Protocol, is shaped by the underlying problem structure. In other words: gains from international cooperation in the issue area primarily accrue to provider countries, giving user countries few economic incentives to agree to far-reaching regulatory standards under international law.

\section{Biopiracy, misappropriation and misuse}

While the term "biopiracy" is not defined under international law, it is conceptually founded in the principle of state sovereignty over natural resources. Principle 02 of the 1992 Rio Declaration affirms that "[s]tates have [...] the sovereign right to exploit their own resources pursuant to their own environmental and developmental policies" (UNCED, 1992). This principle is echoed in the CBD's Article 03, and applies both to GR in their natural habitats within a provider country ("in situ") and GR stored in germplasm collections within the same or a different jurisdiction ("ex situ"). Furthermore, the Convention recognizes that "the authority to determine access to genetic resources rests with the national governments and is subject to national legislation" (CBD, Article 15.1). While states shall facilitate access to GR originating within their respective territories (Article 15.2), such access: a) requires their initial authorization, based on what purpose and by whom the resource is to be used (Prior Informed Consent, PIC); and, b) the subsequent negotiation of a bilateral contract between the provider country and the party wishing to utilize the resource (Mutually Agreed Terms, MAT). Bilateral Access and Benefit-Sharing (ABS) contracts define the terms under which a private user may utilize a particular GR and, inter alia, set out the specific details of monetary and/or non-monetary compensation for the provider country. The modalities of benefit-sharing are up to the user and the provider country to agree on and may include up-front payments, royalties, 
sharing of research results, and joint ownership of intellectual property rights or capacity building.

As commercial users lack economic incentives for sharing benefits, CBD Article 15.7 obliges contracting parties to take "legislative, administrative or policy measures [...] with the aim of sharing in a fair and equitable way the results of research and development and the benefits arising from the commercial and other utilization of genetic resources with the Contracting Party providing such resources". As a framework convention, the CBD only creates general rights and obligations related to ABS. Their implementation is the subject of the Nagoya Protocol (see Section 06 below). On the basis of the CBD's distinction between PIC and MAT, however, it is possible to differentiate between two legally distinct types of biopiracy: misappropriation and utilization "in a non-agreed way" (IUCN, 2012, p. 12).

Misappropriation of GR constitutes a case in which a resource has been accessed in violation of the provider country's domestic ABS framework, that is, where PIC has not been obtained. Addressing misappropriation requires the enforcement of third country legislation within a user jurisdiction. Although access to GR in ex situ collections is still subject to the PIC requirement, identifying the country of origin can be a daunting task even where users are, in principle, willing to share the benefits from utilization on fair and equitable terms. GR are frequently passed along larger supply chains, including botanical gardens as well as public and private laboratories. Failure to identify the origin of a resource here may result from the relevant documentation being unavailable or from a user's intent to avoid having to enter into benefit-sharing arrangements. Thus, a major difficulty consists of determining a reasonable amount of effort that users would unsuccessfully have to spend on identifying the country of origin before a GR would be considered as belonging to the "orphan" category for which PIC is unavailable. Parties to the Nagoya Protocol have committed themselves to considering "the need for and modalities of a global multilateral benefit-sharing mechanism" for precisely those cases (Nagoya Protocol Article 10). If such a multilateral benefit-sharing regime were to be established, incentives to declare a resource as being of unknown origin would be weakened, as this would merely switch the applicable benefit-sharing regime instead of avoiding benefit-sharing altogether. 
Once PIC has been granted, user and provider countries enter into bilateral negotiations regarding MAT, that is, the terms of access, benefit-sharing and other relevant modalities such as dispute settlement clauses. As a private contract, non-compliance with MAT is of a different legal nature than noncompliance with PIC, as it constitutes a breach of contractual obligations under private law (CHIAROLLA, 2012). The existence of contractual rights and obligations allows for better monitoring of utilization. While instances of misappropriation may simply go unnoticed due to patent offices not routinely verifying whether PIC and MAT have been established, misuse is easier to detect as the identity of the user and the purpose of utilization are known to the provider country. Further, enforcement is facilitated through the existence of contractual obligations.

\section{The Nagoya Protocol: scope, user measures, international access standards}

Negotiations on an international ABS regime were mandated by CBD COP 7, 2004 and the Nagoya Protocol was adopted at COP 10 in 2010 (BUCK and HAMILTON, 2011; FREIN and MEYER, 2010). The present section addresses the Nagoya Protocol's design in terms of compliance provisions and access standards for GR falling within its scope. The Protocol's "user measures" (Articles 15 to 18) create obligations for user countries, to ensure that the utilization of GR within their respective jurisdictions takes place in line with the relevant principles and objectives of the CBD. The "international access standards" (Article 06) attempt to streamline access procedures in provider countries. Those standards are relevant for compliance in those cases where users are willing to enter into negotiated benefit-sharing arrangements, yet are precluded from doing so by bureaucratic or discriminatory legislation. Below, I show that the Protocol is heavy on management and light on enforcement, while leaving sufficient flexibility for national implementation in user countries to exclude significant amounts of GR from its scope. For those GR that remain within its scope, the Protocol and resulting implementing legislation in both provider and user countries will facilitate user compliance by streamlining and simplifying administrative procedures and applicable legislation. However, being weak on enforcement, it 
does little to deter deliberate non-compliance in cases where large commercial stakes are involved.

\section{Scope}

Pursuant to its Article 03, the Protocol applies to all GR, Traditional Knowledge associated with GR and benefits resulting from their utilization falling under CBD Article 15. Read in conjunction with CBD Article 02, this includes "any material of plant, animal, microbial or other origin containing functional units of heredity" which is "of actual or potential value" and under the sovereignty of a party to the CBD. This excludes GR in Areas Beyond National Jurisdiction, such as Antarctica or the high seas. Furthermore, CBD COP 2 has decided that human GR are excluded from the Convention's scope (Decision II/11).

The Protocol's temporal scope was one of the more controversial items of the negotiation process (WALLBOTT et al., 2014, pp. 37-38). From the text, it is unclear whether the Protocol applies only to GR accessed after its entry into force, or whether it extends to post-CBD or even pre-CBD acquisitions. The default interpretation, in line with Article 28 of the Vienna Convention on the Law of Treaties, is that the Protocol applies exclusively to GR accessed after $12^{\text {th }}$ October 2014, its entry into force. Whether the Protocol's Article 3 reference to GR falling under the scope of CBD Article 15 can be construed as implying retroactivity or not, is a legally contentious question. That is, Article 03 could be interpreted as including all GR accessed since the CBD's entry into force in 1993 (IUCN, 2012, p. 72).

The implications of non-retroactivity critically depend on the interpretation of the term "access" which, surprisingly, is defined in neither the CBD nor the Protocol. As access requires the country of origin's PIC and possibly leads to benefit-sharing under MAT, what precisely constitutes "access" has enormous implications for GR in ex situ collections. While those GR have been physically removed from their respective countries of origin, access is still subject to the PIC requirement. "Access" can be understood to have two different meanings: the physical acquisition of a GR in a country of origin, or its utilization in biotechnological innovation processes (TVEDT and SCHEI, 2014). This means that it is unclear whether the Protocol is applicable "at the point of access to GR (in 
provider countries) or at the point of utilization (in user countries)" (WALLBOTT et al., 2014, p. 37). Under the former interpretation, significant amounts of ex situ collections fall outside the Protocol's scope and their utilization will not trigger benefit-sharing obligations subject to the Protocol's compliance provisions. In other words: the Articles 15 to 18 user measures would only apply to GR acquired from their respective countries of origin after $12^{\text {th }}$ October 2014 . It is precisely this ambiguity which the EU implementing legislation exploits (see Section 07 below).

\section{User measures}

The Protocol's Articles 15 to 18 oblige parties to create measures for ensuring that utilization of GR within their jurisdictions takes place in accordance with the principles of PIC and MAT, as well as with the benefit-sharing objective. Article 15 requires each party to take "appropriate, effective and proportionate legislative, administrative or policy measures to provide that genetic resources utilized within its jurisdiction have been accessed in accordance with prior informed consent and that mutually agreed terms have been established". Article 16 applies a similar provision to traditional knowledge associated with GR. Articles 15 and 16, addressing compliance with the domestic ABS frameworks of provider countries, are primarily relevant for cases of misappropriation. Article 18.2, requires parties to provide opportunities for legal recourse; and, Article 18.3 requires them to take "appropriate measures" regarding access to justice and the "mutual recognition and enforcement of foreign judgments and arbitral awards". Finally, Article 17 spells out compliance support procedures applicable to both Articles 15 and 16. It creates standards for an internationally recognized certificate of compliance and obliges parties to designate "checkpoints" which "collect or receive, as appropriate, relevant information related to prior informed consent, to the source of the genetic resource, to the establishment of mutually agreed terms, and/or to the utilization of genetic resources, as appropriate" (Article 17.1.a.i). Users are required to provide the "relevant information" at the appropriate checkpoint, and may use the certificate of compliance to do so (Article 17.1.a.iii). While the certificate of compliance is conceptually close to a disclosure of origin requirement, long discussed both in $\mathrm{CBD}$ and other international forums (BLAKENEY, 2005; CORREA, 2005; DUTFIELD, 2005; HOARE and TARASOFSKY, 
2007), it does not necessarily have legal effect under patent law. Parties are not required to designate patent offices as checkpoints, and failure to produce the certificate (or equivalent documentary evidence) only requires the relevant party to take "appropriate, effective and proportionate measures" pursuant to Articles 15.2 or 16.2 .

\section{International access standards}

A common problem with access to GR is intransparent, bureaucratic or discriminatory ABS legislation in provider countries (MEDAGLIA et al., 2012, pp. 66-71). The Protocol's "International Access Standards" (Article 06) were originally introduced into the negotiations by the EU as a compliance support measure (ENB, 2008). Article 6.3 obliges parties that have chosen to request PIC for GR within their jurisdiction to, inter alia, take "legislative, administrative or policy measures, as appropriate" in order to provide for "legal certainty, clarity and transparency" regarding domestic ABS frameworks and for "fair and nonarbitrary rules". From a management perspective, those international access standards are likely to enhance compliance, as users of GR often face complex and intransparent access legislation in provider countries (RENNER et al., 2012). We should expect rule-guided behavior to dominate over gain maximization in cases where few commercial stakes are involved, such as in non-commercial academic research (BIBER-KLEMM et al., 2014). For such purposes, the Protocol obliges parties to create simplified access measures (Article 8a). By streamlining procedures, compliance with the PIC and MAT requirements will be enhanced, at least for those actors without a clear preference for commercial gains.

\section{Implementing the Nagoya Protocol: the case of the EU}

The degree to which fair and equitable benefit-sharing will be achieved depends, to a large extent, on the implementation of the Nagoya Protocol in major user jurisdictions. With the US being a non-party, the EU possesses the world's largest market for GR falling under the scope of the CBD and the Protocol. During the negotiation of the Protocol, the EU showed itself willing to engage with the demands of provider countries by conceding the need for a legally binding 
instrument early on in the process, while insisting throughout that any compliance mechanisms must not be linked to patent law (OBERTHÜR and RABITZ, 2014).

The EU is a contracting party, as a Regional Economic Integration Organization, to the CBD. The Nagoya Protocol is a mixed agreement: a number of its provisions fall under the shared competence of the EU and its member states; others fall under exclusive Union competence (Treaty on the Functioning of the European Union, Articles 03 and 04). Regulation 511/2014, approved by the European Parliament and the Council in March and April 2014, creates a due diligence standard for users utilizing genetic resources and the traditional knowledge associated with genetic resources within EU member states. The Regulation applies to GR accessed after the Protocol's entry into force and defines "access" as "the acquisition of genetic resources or of traditional knowledge associated with genetic resources in a party to the Nagoya Protocol" (Article 3.3). As discussed in Section 06, this implies that the future utilization of GR acquired before $12^{\text {th }}$ October 2014 and stored in ex situ collections of EU member states is not subject to the PIC requirement. As both the CBD and the Protocol leave "access" undefined, the EU interpretation of the term excludes large amounts of samples, collected in the past but usable in the future, from the scope of the Regulation.

The Regulation establishes three compliance mechanisms: best practices employed by users and recognized by the Commission (Article 08), the establishment of a central register to which collection holders may voluntarily accede (Article 05) and the obligation of users to exercise due diligence "to ascertain that genetic resources and traditional knowledge associated with genetic resources which they utilize have been accessed in accordance with applicable access and benefit-sharing legislation or regulatory requirements, and that benefits are fairly and equitably shared upon mutually agreed terms" (Article 4.1). I address each in turn.

First, GR included in the voluntary internet-based Register of Collections may only be transferred to third parties subject to documentary evidence that they were acquired in accordance with the appropriate ABS laws and/or regulations and, where relevant, that MAT have been established (Article 5.3). The Register also requires the use of unique identifiers and tools for tracking and monitoring 
the transfer of resources to third parties (Article 5.3.d-e). Second, the Commission may recognize best practices when they are considered to implement effectively the due diligence and monitoring requirements under Articles 04 and 07. Recognition shall be withdrawn when there is evidence that a best practice is ineffective in facilitating user compliance. Following a best practice does not automatically exempt users from exercising due diligence. However, through the recognition of best practices, the Commission can establish a set of voluntary standards that facilitate compliance.

Third, Article 4.3 requires users to "seek, keep and transfer" an internationally recognized certificate of compliance or documentation of date and place of access, description of the resource and the direct source from which it was obtained, whether ABS-related rights and obligations, and, where available, access permits and/or MAT, exist. Pursuant to Article 4.5, where users supply insufficient information or where access and utilization are subject to persistent legal uncertainty, users are obliged either to obtain an access permit and establish MAT or to cease utilization. Possession of the Certificate or equivalent information needs to be documented at the "stage of final development of a product developed via the utilization of genetic resources" (Article 7.2.). Additionally, competent authorities are required to actively check for user compliance, including the possible use of "on-the-spot" checks (Article 09). Where users are in noncompliance, member states are required to implement "effective, proportionate and dissuasive" penalties (Article 11.2).

The Regulation emphasizes management over enforcement. Where users are intrinsically motivated to comply, the existence of best practices and information-sharing under the Register helps users to identify the existence of PIC requirements and to enter into benefit-sharing arrangements based on MAT. Particularly, for non-commercial academic research, the level of compliance will likely be enhanced due to greater transparency under the Register, while compliance costs are reduced through recognized best practices. Additionally, the requirement that those recipients of public research funding, which are involved in the utilization of GR, declare their exercise of due diligence (Article 7.1) raises the awareness of the legal framework. 
In principle, however, the enforcement component of the Regulation allows users to shirk their benefit-sharing obligations easily. First, where a certificate of compliance is considered unavailable, the minimum threshold for utilization to be compliant with Article 04 is documentation regarding date and place of access, description of the resource in question, its direct source, and whether rights and obligations regarding ABS are present or absent. Access permits and MAT, on the other hand, are only required "where available" (Article 4.3.b). Here, the difficulty lies in distinguishing between genuine orphan GR for which the country of origin cannot be determined anymore, and GR which are falsely declared to be of unknown origin in order to avoid the sharing of benefits. Considering the frequently long supply chains through which GR are transferred before utilization takes place, the requirement to disclose the immediate source may not be enough to establish whether or not utilization takes place in accordance with PIC and MAT.

Second, considering the difficulty in determining the precise date at which a GR has been added to an ex situ collection, pre-dating the time of access to before the Protocol's entry into force removes the resource in question from the scope of the Regulation.

Finally, the Regulation delegates the question of sanctions to the EU member states, requiring merely that penalties be "effective, proportionate and dissuasive" (Article 11.2). While member state implementation, including the designation of competent national authorities, is still ongoing, the basic dilemma is that countries with strong sectoral interests possess considerable leeway in determining the penalties intended to deter domestic users from non-compliance with third country legislation.

\section{Conclusions}

The Nagoya Protocol has been described as a "masterpiece in creative ambiguity" (ENB, 2010, p. 26), which has "left experts puzzled about what exactly has been agreed on for many critical issues, [...] giving rise to a range of partially conflicting interpretations" (ICTSD, 2010). Textual ambiguity has allowed parties holding widely differing interests to agree on a legally binding outcome after a difficult negotiation process which, until the very end, was in danger of collapsing 
(NIJAR, 2011, pp. 03-15). While the international constellation of interests explains the lack of precision and stringency, the Protocol's enforcement components are unlikely to contribute significantly to the implementation of the objective of fair and equitable benefit-sharing. Assuming that "[w]hen a company's shareholders want the largest return from their investment, [...] voluntary benefit sharing is an illusion" (TVEDT, 2014), insufficient enforcement provisions translate directly into low regime effectiveness.

At the same time, we should expect the international access standards and facilitated access procedures for non-commercial research to enhance compliance in cases where commercial stakes are absent. The Protocol thus constitutes a "mixed bag", with its enforcement components falling far short of the demands which provider countries have been voicing for over a decade. However, considering the overall problem structure, that is, the zero-sum nature of (particularly monetary) benefit-sharing, strongly diverging economic interests among key actors, practical difficulties with monitoring the transnational utilization of GR, as well as pervasive uncertainty regarding the global extent of biopiracy and its costs, the Protocol highlights how regime design is (at least partially) endogenous to problem structure (MITCHELL, 2006). As domestic measures within major user jurisdictions are indispensable for implementing the benefit-sharing objective, it is thus not surprising that provider countries, being the demandeurs of the Protocol, yet lacking significant leverage in the negotiation process, failed to achieve a more favorable outcome.

Revised by Peter Laspina Submitted in February 2014 Accepted in February 2015

\section{References}

ANDERSEN, Regine (2008), Governing Agrobiodiversity. Plant genetics and developing countries. Aldershot: Ashgate. 442 p.

BARDI, Marcelo A.G.; GUTIERREZ-OPPE, Evelyn and POLITANO, Rodolfo (2011), Traditional Knowledge Products in Latin America and their Misappropriation. Journal of Intellectual Property Law \& Practice. Vol. 06, № 01, pp. 34-42. 
BIBER-KLEMM, Susette; DAVIS, Kate; GAUTIER, Laurent, and MARTINEZ, Sylvia I. (2014), Governance Options for ex-situ Collections in Academic Research. In: OBERTHÜR, Sebastian and ROSENDAL, Kristine G. (eds.), Global Governance of Genetic Resources. Access and Benefit-Sharing after the Nagoya Protocol. New York/London: Routledge. pp. 213-230.

BLAKENEY, Michael (2005), Proposals for the Disclosure of Origin of Genetic Resources in Patent Applications. Study for the World Intellectual Property Organization, WIPO/IP/GR/05/01. London: University of London.

BRAND, Ulrich; GÖRG, Cristoph; HIRSCH, Joachim and WISSEN, Markus (2008), Conflicts in Environmental Regulation and the Internationalization of the State. Contested terrains. London/New York: Routledge.

BREITMEIER, Helmut; UNDERDAL, Arild and YOUNG, Oran R. (2011), The Effectiveness of International Environmental Regimes: Comparing and Contrasting Findings from Quantitative Research. International Studies Review. Vol. 12, № 04, pp. 579-605.

BUCK, Matthias and HAMILTON, Claire (2011), The Nagoya Protocol on Access to Genetic Resources and the Fair and Equitable Sharing of Benefits Arising from their Utilization to the Convention on Biological Diversity. Review of European Community \& International Environmental Law. Vol. 20, № 01, pp. 47-61.

CHAYES, Abram and CHAYES, Antonia H. (1993), On compliance. International Organization. Vol. 47, № 02, pp. 175-205.

CHIAROLLA, Claudio (2012), The Role of Private International Law under the Nagoya Protocol. In: MORGERA, Elisa; BUCK, Matthias and TSIOUMANI, Elsa (eds.), The 2010 Nagoya Protocol on Access and Benefit- sharing in Perspective: Implications for International Law and Implementation Challenges. Leiden/Boston: Martinus Nijhoff. pp. 423-450.

CORREA, Carlos (2005), The Politics and Practicalities of a Disclosure of Origin Obligation. QUNO Occasional Paper 16. Geneva: Quaker United Nations Office.

DOWNS, George W.; ROCKE, David M. and BARSOOM, Peter N. (1996) Is the Good News about Compliance Good News about Cooperation? International Organization. Vol. 50, № 03, pp. 379-406.

DUTFIELD, Graham (2005), Thinking Aloud on Disclosure of Origin. QUNO Occasional Paper 18. Geneva: Quaker United Nations Office.

ENB (2008), Summary of the Sixth Meeting of the Working Group on Access and Benefit-Sharing of the Convention on Biological Diversity. Earth Negotiation Bulletin. Vol. 09, № 416.

ENB (2010), Tenth Meeting of the Conference of the Parties to the Convention on Biological Diversity. Earth Negotiation Bulletin. Vol. 09, № 544. 
FREIN, Michael and MEYER, Hartmut (2010), Das ABC des ABS-Regimes. Biopiraterie und die Verhandlungen auf dem Weg nach Nagoya. Bonn: Evangelischer Entwicklungsdienst.

GUNNINGHAM, Neil and KAGAN, Robert A. (2005), Regulation and Business Behavior. Law \& Policy. Vol. 27, № 02, pp. 213-218.

HAMILTON, Claire (2006), Biodiversity, Biopiracy and Benefits: What Allegations of Biopiracy Tell us about Intellectual Property. Developing World Bioethics. Vol. 06, № 03, pp. 158-173.

HELM, Carsten and SPRINZ, Detlef (2000), Measuring the Effectiveness of International Environmental Regimes. Journal of Conflict Resolution. Vol. 44, № 05, pp. 630-652.

HOARE, Alison A. and TARASOFSKY, Richard G. (2007), Asking and Telling: Can 'Disclosure of Origin' Requirements in Patent Applications Make a Difference? The Journal of World Intellectual Property. Vol. 10, № 02, pp. 149-169.

HOVI, Jon; SPRINZ, Detlef F. and UNDERDAL, Arild (2003), The Oslo-Potsdam Solution to Measuring Regime Effectiveness: Critique, Response, and the Road Ahead. Global Environmental Politics. Vol. 03, № 03, pp. 74-96.

ICTSD (2010), CBD clinches ABS protocol in Nagoya. BIORES News. $8^{\text {th }}$ November 2010. International Centre for Trade and Sustainable Development.

IUCN (2012), An Explanatory Guide to the Nagoya Protocol on Access and BenefitSharing. International Union for the Conservation of Nature, Environmental Policy and Law Paper № 83.

KRATOCHWIL, Friedrich (2011), Thrasymmachos Revisited: On the Relevance of Norms and the Study of Law for International Relations. In: The Puzzles of Politics. Inquiries into the Genesis and Transformations of International Relations. Edited by KRATOCHWIL, Friedrich. Abdingdon: Routledge. pp. 8398.

LIANG, Bryan A. (2011), Global Governance: Promoting Biodiversity and Protecting Indigenous Communities Against Biopiracy. Journal of Commercial Biotechnology. Vol. 17, № 03, pp. 248-253.

MARCH, James G. and OLSEN, Johan P. (1998), The Institutional Dynamics of International Political Orders. International Organization. Vol. 52, № 04, pp. 943-969.

MAY, Peter J. (2005), Regulation and Compliance Motivations: Examining Different Approaches. Public Administration Review. Vol. 65, № 01, pp. 31-44.

MEDAGLIA, Jorge C.; PERRON-WELCH, Frederic and RUKUNDO, Olivier (2012), Overview of National and Regional Measures on Access to Genetic Resources and Benefit-Sharing. Challenges and Opportunities in Implementing the 
Nagoya Protocol. Montreal: Centre for International Sustainable Development Law.

MGBEOJI, Ikechi (2006), Global Biopiracy: Patents, Plants and Indigenous Knowledge. Vancouver: UBC Press. 336 p.

MITCHELL, Ronald B. (2006), Problem Structure, Institutional Design, and the Relative Effectiveness of International Environmental Agreements. Global Environmental Politics. Vol. 06, № 03, pp. 72-89.

MYERS, Norman; MITTERMEIER, Russel A.; MITTERMEIER, Cristina G., FONSECA, Gustavo A.B. da and KENT, Jennifer (2000), Biodiversity Hotspots for Conservation Priorities. Nature. Vol. 403, № 6772, pp. 853-858.

NIJAR, Gurdial Sing (2011), The Nagoya Protocol on Access and Benefit-Sharing of Genetic Resources: an analysis. CEBLAW Brief. Kuala Lumpur: Centre of Excellence for Biodiversity Law.

OBERTHÜR, Sebastian and RABITZ, Florian (2014), On the EU's Performance and Leadership in Global Environmental Governance: The Case of the Nagoya Protocol. Journal of European Public Policy. Vol. 21, № 01, pp. 39-57.

RATTRAY, Gillian N. (2002), The Enola Bean Patent Controversy: Biopiracy, Novelty and Fish-and-Chips. Duke Law \& Technology Review. Vol. 01, № 01, pp. 01-08.

RENNER, Swen C.; NEUMANN, Dirk; BURKART, Michael; FEIT, Ute; GIERE, Peter; GRÖGER, Andreas; PAULSCH, Axel; PAULSCH, Cornelia; STERZ, Mario and VOHLAND, Katrin (2012), Import and Export of Biological Samples from Tropical Countries - Considerations and Guidelines for Research Teams. Organisms Diversity \& Evolution. Vol. 12, № 01, pp. 81-98.

ROBINSON, Daniel (2010), Confronting Biopiracy: Challenges, Cases and International Debates. Oxon: Routledge. 228p.

ROSENDAL, Kristin G. (2000), The Convention on Biological Diversity and Developing Countries. Boston: Kluwer Academics. 696p.

SHERIDAN, Cormac (2005), EPO Neem Patent Revocation Revives Biopiracy Debate. Nature Biotechnology. Vol. 23, № 05, pp. 511-512.

SHIVA, Vandana (2001), Protect or Plunder? Understanding Intellectual Property Rights. London: Zed Books. 146 p.

TVEDT, Morten W. (2014), Beyond Nagoya. Towards a legally functional system of access and benefit sharing. In: OBERTHÜR, Sebastian and ROSENDAL, Kristine G. (Eds.), Global Governance of Genetic Resources. Access and Benefit-Sharing after the Nagoya Protocol. New York/London: Routledge. pp. 158-177. 
TVEDT, Morten W. and SCHEI, Peter (2014), The Term 'Genetic Resources': Flexible and Dynamic While Providing Legal Certainty?. In: OBERTHÜR, Sebastian and ROSENDAL, Kristine G. (Eds.), Global Governance of Genetic Resources. Access and Benefit-Sharing after the Nagoya Protocol. New York/London: Routledge. pp. 18-32.

UNDERDAL, Arild (2002), One Question, Two Answers. In: Environmental Regime Effectiveness: Confronting Theory with Evidence. Edited by MILES, Edward L.. Cambridge, MA: MIT Press. pp. 03-45.

UNCED (1992), Rio Declaration on Environment and Development. Rio de Janeiro, United Nations Conference on Environment and Development. 3rd to $14^{\text {th }}$ June, 1992.

UNITED STATES (2005), Article 27.3(b), Relationship between the TRIPS Agreement and the CBD, and the Protection of Traditional Knowledge and Folklore. Communication by the United States to the TRIPS Council. $8^{\text {th }}$ June 2005. IP/C/W/449.

VAN BEUZEKOM, Brigitte and ARUNDEL, Anthony (2009), OECD Biotechnology Statistics 2009. Paris: Organization for Economic Cooperation and Development.

VIVAS-EUGUI, David (2012), Bridging the Gap on Intellectual Property Rights and Genetic Resources in WIPO's Intergovernmental Committee (IGC). International Centre for Trade and Sustainable Development, Issue paper № 34 . Geneva.

WALLBOTT, Linda; WOLFF, Franziska and POZAROWSKA, Justyna (2014), The Negotiations of the Nagoya Protocol: Issues, Coalitions, and Process. In: Global Governance of Genetic Resources. Access and Benefit Sharing after the Nagoya Protocol. Edited by OBERTHÜR, Sebastian and ROSENDAL, Kristin G. Abingdon: Routledge. pp. 33-59.

WILKE, Marie (2013), The World Health Organization's Pandemic Influenza Preparedness Framework as a public health resources pool. In: Common Pools of Genetic Resources: Equity and Innovation in International Biodiversity Law. Edited by KAMAU, Evanson G. and WINTER, Gerd. London: Routledge. pp. 315342.

WYNBERG, Rachel and CHENNELLS, Roger (2009), Green diamonds of the South: An Overview of the San-Hoodia Case. In: WYNBERG, Rachel; SCHROEDER, Doris and CHENELLS, Roger. Indigenous Peoples, Consent and Benefit Sharing. Lessons from the San-Hoodia case. Dordrecht: Springer. pp. 89-124.

YOUNG, Oran (2001), Inferences and Indices: Evaluating the Effectiveness of International Environmental Regimes. Global Environmental Politics. Vol. 01, № 01 , pp. 99-121.

YOUNG, Oran (2003), Determining Regime Effectiveness: A Commentary on the Oslo-Potsdam Solution. Global Environmental Politics. Vol. 03, № 03, pp. 97104. 